This is the peer reviewed version of the following article: Cerqueira, M., Rey, S., Silva, T., Featherstone, Z., Crumlish, M. and MacKenzie, S. (2016), Thermal preference predicts animal personality in Nile tilapia Oreochromis niloticus. Journal of Animal Ecology, 85: 1389-1400. doi:10.1111/1365-2656.12555, which has been published in final form at http://doi.org/10.1111/13652656.12555. This article may be used for non-commercial purposes in accordance With Wiley Terms and Conditions for self-archiving. 
Received Date : 18-Dec-2015

Revised Date : 28-Apr-2016

Accepted Date : 13-May-2016

Article type : Standard Papers

Editor $\quad$ : Sissel Jentoft

Section : Behavioural Ecology

\section{Thermal preference predicts animal personality in Nile tilapia Oreochromis niloticus.}

M. Cerqueira ${ }^{a}$, S. Rey ${ }^{b}$, T. Silva ${ }^{c}$, Zoe Featherstone ${ }^{b}$, Margaret Crumlish $^{b}$, and S. MacKenzie ${ }^{b^{*}}$

${ }^{a}$ Centro de Ciências do Mar (CCMAR), Universidade do Algarve, Faro, Portugal.

${ }^{b}$ Institute of Aquaculture, School of Natural Sciences, Pathfoot Building, FK9 4LA, University of Stirling, UK.

'SPAROS Lda., Área Empresarial de Marim, Lote C, 8700-221 Olhão, Portugal.

*Correspondence to be sent to: simon.mackenzie@stir.ac.uk

\section{Summary}

1. Environmental temperature gradients provide habitat structure in which fish orientate and individual thermal choice may reflect an essential integrated response to the environment. The use of subtle thermal gradients likely impacts upon specific physiological and behavioural processes reflected as a suite of traits described by animal personality. In this study we examine the relationship between thermal choice, animal personality and the impact of infection upon this interaction.

2. We predicted that thermal choice in Nile tilapia Oreochromis niloticus reflects distinct personality traits and that under a challenge individuals exhibit differential thermal distribution.

This article has been accepted for publication and undergone full peer review but has not been through the copyediting, typesetting, pagination and proofreading process, which may lead to differences between this version and the Version of Record. Please cite this article as doi: 10.1111/1365-2656.12555

This article is protected by copyright. All rights reserved. 
3. Nile Tilapia were screened following two different protocols: 1) a suite of individual behavioural tests to screen for personality and 2 ) thermal choice in a custom-built tank with a thermal gradient ( $T_{C H}$ tank) ranging from 21 to 33 으. A first set of fish were screened for behaviour and then thermal preference and a second set were tested in the opposite fashion; thermal then behaviour. The final thermal distribution of the fish after 48 $\mathrm{h}$ was assessed reflecting final thermal preferendum. Additionally, fish were then challenged using a bacterial Streptococcus iniae model infection to assess the behavioural fever response of proactive and reactive fish.

4. Results showed that individuals with preference for higher temperatures were also classified as proactive with behavioural tests and reactive contemporaries chose significantly lower water temperatures. All groups exhibited behavioural fever recovering personality-specific thermal preferences after 5 days.

5. Our results show that thermal preference can be used as a proxy to assess personality traits in Nile tilapia and it is a central factor to understand the adaptive meaning of animal personality within a population. Importantly, response to infection by expressing behavioural fever overrides personality related thermal choice.

Keywords: thermal preference, animal personality, environmental choice, behavioural fever, Nile Tilapia, physiological regulation.

\section{Introduction}

Environmental temperature influences all aspects of an organism's physiology and behaviour, from reproduction to growth, and this dynamic interaction with the environment impacts upon fitness and survival. In mobile ectotherms, such as fish and insects, body temperature closely follows environmental temperature and can only be modified by behavioural means. This behavioural regulation occurs across different temporal scales including daily and seasonal cycles. This impacts upon the basal metabolic rates of ectotherms where small changes in environmental temperature may result in significant metabolic fluctuations (Clarke and Fraser, 2004). For example, fish navigate thermal gradients to attain a preferred thermal optima to improve physiological and in some cases reproductive performance (Huey \& Bennett 1987; Huey \& Kingsolver 1989; Pawson, Pickett \& Witthames 2000; Angilletta Jr, Niewiarowski \& Navas 2002). Recently in Drosophila larvae 
thermosensory neurons where shown to provide the basis for thermotaxis coupled to environmental navigation in a fluctuating thermal environment highlighting the importance of thermal perception (Klein et al, 2014). Thermal optimum is defined as the temperature that maximizes physiological performance at an individual level. Under normal conditions if performance is linked to fitness, natural selection should favour a tight relationship between preferred body temperature and the preferred thermal optima by means of regulatory behaviour (Huey \& Bennett 1987). Such behaviour can be seen as a thermoregulatory response with a positive trade-off between energy demand and physiological requirements (Rey, Digka \& MacKenzie 2015). The thermal optimum for an individual is defined as the final thermal preferendum (Fry 1947). Calculation of this preferendum is measured for each individual 24-96 $\mathrm{h}$ after exposure to an adequate thermal choice. This final temperature represents the interaction between environmental demand and an individual's capacity to respond to such demands. The final thermal preferendum calculated on an individual level has since been used as a mean temperature preference guide in fish (Rey, Digka \& MacKenzie 2015).

Recent progress addressing animal personalities (Overli et al. 2007; Huntingford et al. 2010; Silva et al. 2010; Martins et al. 2011; Castanheira et al. 2013b; Rey et al. 2013; Herrera et al. 2014) has highlighted a central role for individual variation in ecological and environmental challenges (Sih, Bell \& Johnson 2004; Reale et al. 2007) and as a tool for resolving variation (MacKenzie, et al. 2009). Animal personality traits have been described as underlying tendencies that affect behaviour across contexts, that are stable over time and that vary across individuals (Reale et al. 2007; Dingemanse et al. 2010). Typically, animals categorized as 'proactive' (active coping or bold), "intermediate" (more flexible individuals) or 'reactive' (passive coping or shy) show distinct differences in behavioural profiles for the same measured variable, such as risk taking and exploration, aggression or feeding (Rey et al. 2013; Castanheira et al. 2015). Among fish, there is scarce information linking personality traits and physiological profiles, particularly with respect to individual differences in adaptability, i.e. optimal conditions created for proactive individuals are likely to be different from those of reactive individuals (Rey, Digka \& MacKenzie 2015) with ecological relevance. On one hand, a proactive individual characterized by increased foraging activity may take more risks to attain more food (Finstad et al. 2007) and therefore is more prone to predation risks (Stamps 2007) or to being captured (Biro \& Dingemanse 2009), suggesting higher internal energetic requirements with higher metabolic costs. In contrast, a reactive individual can be characterized by low levels of aggression, immobility and avoidance behaviour under aversive events (see review of Castanheira et al. (2015) that may reflect lower metabolic demands. Recently, Rey, Digka

This article is protected by copyright. All rights reserved. 
\& MacKenzie (2015) using the zebrafish, Danio rerio, as a model showed that proactive and reactive animal personalities express different thermal preferendum and activity patterns when a thermal choice is available. Parallel research showed the effect of fluctuations in temperature on the personality of juvenile coral reef fish, reflected by behavioural variation among and within individuals (Biro, Beckmann \& Stamps 2009).

Based on the fact that fish behaviour reflects individual differences in physiological needs, the prospect to use thermal preference as a mass-screening paradigm is attractive. Different experimental screening methods for personality traits along a proactive-reactive continuum have being used with Nile tilapia as a model (Barreto et al. 2009; Barreto \& Volpato 2011; Martins, Conceição \& Schrama 2011a; Martins, Conceição \& Schrama 2011b; VeraCruz et al. 2011), with the disadvantage of them being intensive time consuming assays. In this study we aimed to firstly assess if final thermal preferendum played a pivotal role in determining the distribution pattern of Nile tilapia with different personalities and secondly to validate final thermal preferendum as a new physiological paradigm to screen for personality traits. In a final experiment we further explored how a bacterial infection impacts upon the expression of behavioural fever in distinct animal personalities.

\section{Material and Methods}

\section{Fish and housing conditions}

Nile tilapia (O.niloticus; wild-type and HomoGold strains) were obtained at the Institute of Aquaculture, University of Stirling, UK. Prior to the experiments, these fish had been reared together, each family, in the same tanks under normal stocking conditions. Fish were kept in a $500 \mathrm{~L}$ fiberglass tank within a RAS system with a continuous water flow. Animals were reared under a 12:12 light-dark cycle and the mean water temperature was of $26.8 \pm 1.5 \stackrel{\circ}{\circ}$. Aeration was supplied through an air stone and fish were fed with a commercial diet (Skretting® Trout Standard Expanded) twice a day.

\section{Experimental protocol and procedures}

Initial trials, Oreochromis niloticus (wild-type, $n=54$ ) were performed to establish the distribution of behavioural phenotypes and behavioural consistency over time. Subsequent experiments using a population of O.niloticus (homogold, $\mathrm{n}=350$ ) were then carried out due to availability of stocks. The consistency of

This article is protected by copyright. All rights reserved. 
behavioural responses between these two populations was analysed using DAl data (see below) and is shown in Fig. S2. Prior to screening, individuals were sorted for size and weight and extremes discarded. Selected animals with mean weight of $8.18 \pm 1.55 \mathrm{~g}$ were moved to 3 smaller holding tanks, at high density in order to avoid aggression: $20 \mathrm{~L}$ white rounded tanks on a recirculation system $(37 \mathrm{~cm}$ diameter $\mathrm{x} 28 \mathrm{~cm}$ height, with a drainage tube in the centre $3 \mathrm{~cm}$ diameter and $20 \mathrm{~cm}$ height) and acclimated for 3 weeks prior to behavioural tests $(\mathrm{n}=96 / \operatorname{tank} ; \mathrm{N}=288$ ). A total of 94 animals with mean weight of $10.43 \pm 1.33 \mathrm{~g}$ were individually tested for Duration of Appetite Inhibition (DAI latency) distribution and net restraining behaviour ( $\mathrm{n}=94$ ) in parallel tanks to those they were held in (VeraCruz et al., (2011). To test for behavioural consistency, the DAI latency measures test was repeated 24 hours after the first feeding event. After the analysis, the distribution regarding the DAI latency was determined and used as a baseline to discriminate the population by personality and establish the corresponding cut-off DAI latencies. Animals were not individually tagged in our experiments and behavioural screening was individually performed before designation of personality.

\section{Personality screening}

A further eighty-four fish (from the 288 fish selected stock) with a mean weight of $15.34 \pm 2.33 \mathrm{~g}$ were individually housed in rows of 12 parallel white rounded tanks of $20 \mathrm{~L}$, as used during stocking. Behaviour was video recorded (HD Webcam C615, Logitech®, USA) for posterior analysis. Cameras were placed above the tanks and used for test 1, 3 and 4. Each fish was subjected to the following individual tests:

1. Novel environment, NE - Screening for novel environment and social isolation was performed immediately after the introduction of the fish into the tank. The first 3 minutes were observed and analysed for swimming activity (\% of time the fish took to explore the new environment and described as the fish movement in the water column or at the bottom at any speed or intensity of body movements). Fish were left for one hour to habituate to these new conditions.

2. Ventilation frequency, VF - After one hour of habituation, aeration and water flow were withdrawn to facilitate behavioural measurements. Animals were habituated for $10 \mathrm{~min}$ before data recording. Ventilation frequency (opercula movements/minute) was taken by direct observation measuring the time it takes a fish to complete 20 successive opercula or mouth movements within one minute across three consecutive minutes.

This article is protected by copyright. All rights reserved. 
When time is higher, VF is lower and fish categorized as proactive (Barreto et al., 2009, 2011). Water flow was then restarted and fish were left to habituate for $30 \mathrm{~min}$.

3. Duration of appetite inhibition, DAI - Latency to reassume feeding after the onset of the food. The test lasted for a maximum of 10 minutes. Latencies to reassume feeding after isolation (DAI latency), latency to first movement (lat2move) and total feed intake (FI) were recorded. According to preliminary trials, fish with DAI latencies shorter than 5 min were categorized as proactive, 5-10 minutes were intermediates and > 10 minutes were categorized as reactive individuals. To check for feeding behaviour consistency, this test was repeated twice (run 1 and run 2: $\mathrm{DAl}_{1}$ and $\mathrm{DAl}_{2}$ ) with an interval between runs of $24 \mathrm{~h}$.

4. Net restraining, NR- The net restraining test consisted of holding each fish individually in an emerged net for $1 \mathrm{~min}$. While in the net, the following behaviours were measured: 1) latency to first escape attempt (lat2escape: time in seconds taken by each fish to show an escape attempt; escape attempt was defined as an elevation of the body from the net), 2) number of escape attempts (total escapes) and 3) total time spent on escape attempts (time escape: total time in seconds taken by each fish escaping since the first to the last escape attempts). All animals were initially grouped by their $\mathrm{DAl}_{1}$ and $\mathrm{DAl}_{2}$ latency, and then settled in holding tanks separated according to their personality traits (homogeneous groups). The results of the remaining tests were used to assess correlations between different behavioural paradigms and confirm the classifications performed using the DAI latency cut-offs. Fish were kept in groups of 30 before the group test.

\section{Temperature preference chamber test}

Thermal preference was assessed in a custom-built multi-chamber tank (adapted from Rey, Digka \& MacKenzie (2015)) (Fig. S1) firstly under constant temperature and then under a continuous thermal gradient allowing the temperature preference of each group to be recorded over a $48 \mathrm{~h}$ time period. The dimension of the tank was adapted to the size of the fish, $126 \mathrm{~L}(140 \times 30 \times 30 \mathrm{~cm})$ and divided with 6 transparent glass screens to create 7 equal interconnected chambers. Each screen had a hole at the centre $(10 \mathrm{~cm}$ diameter; $20 \mathrm{~cm}$ from the bottom) to allow connection between chambers and support ease of movement of the fish. Mechanical filters were placed in the 5 central chambers and the bottom gravel covered. Two custom-built multi-chamber tanks were used under different conditions: 1 ) Thermal gradient $\left(T_{C H}\right)$ and 2) Thermal restriction $\left(T_{R}\right)$. Three video cameras (Linksys ${ }^{\circledR}$ webcams) provided continuous monitoring of the tank chambers with automatic recording

This article is protected by copyright. All rights reserved. 
(Fisheye software, UAB; see Rey, Digka \& MacKenzie (2015) for details). Thermal gradient was first tested and optimized (Fig. S2) to ranges between $20.92 \pm 0.04 \stackrel{\circ}{ } \mathrm{C}$ (chamber 1) to $33.08 \pm 0.08$ oc (Chamber 5), with a mean difference in temperature of $3.04 \pm 0.10 \stackrel{\circ}{\circ}$ between each chamber. Extreme lateral chambers were operated as cooling (mean temperature $16 \pm 0.02 \stackrel{\circ}{\circ}$ ), by means of a cooler system and a pump, and heating chambers (mean temperature $42 \pm 0.02 \stackrel{\circ}{\circ}$ ), by means of a water bath and a pump. Individuals were prevented from entering those chambers by covering the hole in the screens. Thermal restriction conditions were established with the water at rearing temperature $26.58 \pm 0.33 \stackrel{\circ}{C}$ for all the tank chambers. During each test dissolved oxygen was recorded at the beginning and at the end of each trial (Handy Polaris, OxyGuard ${ }^{\circledR}$ International, Denmark). The temperature from each chamber was continuously recorded in the centre of each compartment at the inner wall of the swimming channel for each 15 min with thermocrons iButton (Maxim integrated $^{\circledR}$, USA). Three groups of fish $(n=8)$ were used for each personality trait $(n=24)$ to test for thermal preference. Six groups of naïve fish randomly selected from the stock tanks were used as control groups $(n=48)$. Three of those groups were tested under $T_{R}$ conditions and another three under $T_{C H}$ conditions. Fish were settled in the middle chamber $(26.58 \pm 0.33$ and $26.71 \pm 0.03 \circ \mathrm{C}$, respectively) with the holes covered until all the fish were deployed and covers then immediately removed. Fish were left for 48 hours and filming began immediately. Water was completely replaced between group tests to guarantee equal conditions throughout the trials.

\section{Validation of thermal preference as an indicator of personality}

Eight groups $(n=8)$ and three control groups of naïve fish randomly selected from stocking tanks $(n=88)$ with mean weight of $19.23 \pm 3.21 \mathrm{~g}$ were used to validate thermal preference as a physiological screening proxy without previous behavioural screening. Thermal preference assessment was performed in the same tanks following the same protocol as above with a refined gradient profile of $25.95 \pm 0.2$ 으 to $33.59 \pm 0.3 \stackrel{\circ}{\circ}$, with $1.91 \pm 0.38 \stackrel{\circ}{\circ}$ between chambers. After $48 \mathrm{~h}$, fish were transferred to round tanks (same as previously used with the same water recirculation system) and housed as they were distributed in the different chambers in the $T_{C H}$ tank. All individuals were then subjected to the same battery of behaviour tests described above and moved afterwards to the holding tanks as established groups with homogeneous personality traits and left to recover for 12 days.

This article is protected by copyright. All rights reserved. 


\section{Data acquisition}

Different aspects of fish behaviour were analysed to assess the different personality traits. During the first hour named here as acute thermal period (each min, $n=60$ events), observations were centred upon 1) distribution of fish in the preference chamber for determination of acute thermal preference, 2) individual latencies to exit from initial chamber to side chambers and 3) the number of transitions between chambers for each group. For the last 8 hours of the test, named here as late thermal period ( $7 \mathrm{am}-3 \mathrm{pm} ; \mathrm{n}=33$ events), the distribution of fish was recorded for $25 \mathrm{sec}$, every $15 \mathrm{~min}$ and analysed 'a posteriori' for determination of the final thermal preference. The sequence of the trials was alternate between the personality groups to reduce experimental bias.

\section{Infection Challenge}

An isolate of $S$. iniae recovered from natural infection in Tilapia was used for the bacterial challenge and had been identified using traditional bacterial methods. The isolate was recovered from frozen stocks onto tryptone soya agar (TSA, Oxoid UK) plates, incubated for $48 \mathrm{~h}$ at $28 \stackrel{\circ}{\circ}$ and identity confirmed using Gram, oxidase, motility, O/F methods (Frerichs 1993) and biochemical profile (API Strep, Biomérieux UK). The isolate was passaged through a single fish prior to performing the challenge studies to enhance virulence after longterm storage and the bacterium recovered from the kidney. The challenge inoculum came from a $48 \mathrm{~h}$ growth of a single $S$. iniae colony grown in $45 \mathrm{ml}$ of TSB at $28 \stackrel{\circ}{\circ}$, which was centrifuged at $3500 \mathrm{rpm}$ for $15 \mathrm{~min}$ at $4 \stackrel{\circ}{\circ}$ and the cell pellet re-suspended in sterile physiological saline $(0.85 \% \mathrm{NaCl})$ to give an optical density of 1 . The bacterial concentration was adjusted using sterile saline to give the challenge inoculate. The virulence and adjusted concentrations of bacteria to the weight of the fish was previously validated (Featherstone et al. 2015). Viable colony counts were performed using the Miles and Misra method (Miles, Misra \& Irwin 1938) to check the bacterial concentration and each fish was exposed to $0.1 \mathrm{ml}$ of the bacterial suspension by intraperitoneal injection (i.p.). Homogeneous groups of 8 Tilapia of proactive and reactive individuals were anesthetized with benzocaine and the bacteria administered by i.p. Injection. A control group of naïve fish was used and injected with PBS and were subjected to $\mathrm{T}_{\mathrm{CH}}$ conditions. Test groups are described in table 1. Animals were monitored on a daily basis for 5 days and checked for morbidity/mortality and clinical signs of disease

This article is protected by copyright. All rights reserved. 
(Shoemaker, Klesius \& Evans 2001). The distribution of the fish during the first hour of the first day after deployment and the first 8 hours of the following days was video recorded (7 am - 3 pm; for 25 sec, every 15 $\min ; n=33$ events)

\section{Behavioural and Statistical analysis}

Statistics were performed using IBM SPSS ${ }^{\circledR}$ statistics v19.0, $\mathrm{R}^{\circledR}$ (R Development Core Team) and GraphPad Prism $^{\circledR}$ v6.0 for windows. The assumptions of normality and homoscedasticity were confirmed by analysis of the residuals, with particular attention paid to homogeneity of variances between personality groups (Cleasby \& Nakagawa 2011). Arcsin or $\log _{10}(x+1)$ transformation was applied in the case of non-normally distributed variables. $\mathrm{DAl}_{1}$ and $\mathrm{DAl}_{2}$ latencies were collapsed into principal component scores prior to clustering. The same procedure was taken with the behaviours measured from NR test. Fish were then segregated in three groups using two distinct forms of unsupervised clustering (k-means clustering and hierarchical clustering using Ward's criterion), which displayed full consistency. Pearson correlation was used to verify the repeatability and consistency of individual DAI latencies between both DAI runs. . A one-way ANOVA was used to verify differences between the mean PC1 DAI values for each of the generated clusters and the post hoc Fisher LSD test was performed for specific significant differences. A global Principal component analysis (i.e. using all raw behavioural parameters measured from VF, NE, DAI and NR tests) was used to assess the quality of the separated groups using DAI latencies cut-offs determined during the preliminary test. Using the same variables, Pearson correlation was performed to assess how correlated were the different behaviours measured. To examine the differences between behavioural phenotypes, one-way ANOVA with Fisher LSD post-hoc was used for each of the behavioural paradigms (NE; VF; $\mathrm{DAl}_{1} ; \mathrm{DAl}_{2}$ and NR). For this purpose, behaviours taken during DAI test were collapsed into first component scores using Principal Components Analysis (PCA) for both events. The same approach was used for the behaviours measured from restraining test. The correlation matrix was used to check multicollinearity after varimax rotation. Kaiser-Meyer-Olkin (KMO) test for sample adequacy was always greater than 0.5 and the Bartlett's test of sphericity was significant for all tests. A two-way ANOVA was used to analyse latencies and transitions, after log transformation, as dependent variables with temperature and personality as fixed factors. Both acute and final thermal preference for each of the personality groups was calculated as follows:

This article is protected by copyright. All rights reserved. 


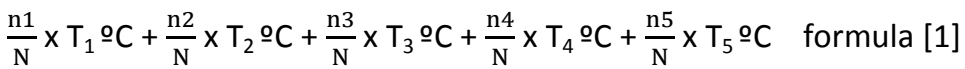

Where $\mathrm{n}_{(\mathrm{i}=1,2 \ldots 5)}$ was the number of fish in the chamber; $\mathrm{N}$ the total number of fish in the tank and $\mathrm{T}_{(\mathrm{x})}$ the mean temperature of the chamber. Significant differences between thermal preferences of the different personality groups were checked afterwards through Kruskal-Wallis test since this remained non-normal after transformation. For pairwise differences a Mann-Whitney U test was used. GLM mixed model was fitted with number of fish as dependent variable and independent variables (and higher order interactions) were selected for inclusion in the model through a backward stepwise likelihood ratio method and examination of the Wald $\chi^{2}$ statistic, to reach the minimum suitable model with the lowest Akaike information criterion (AIC) value. Leverage statistics and residual analysis were used to test the validity of model assumptions. The Wald $\chi^{2}$ was used to test for a significant effect of the temperature or chamber (this last in the case of controls under restriction conditions) and personality on the distribution of the fish over the experimental aquaria, estimated by their coefficients $\beta$ (negative binomial distribution parameter) T-test or Mann-Whitney U test was used for pairwise comparisons between thermal preference of control groups of both gradients (normal or non-normal data, respectively) and Wilcox rank test for comparisons between thermal preference after 2 and 4 days post infection or dpi (non-normal data). Statistical significance was taken at $p<0.05$. The results are expressed as mean \pm standard error of the mean (SE).

\section{Results}

Behavioural screening for personality traits

Group clustering with fish from the same batch was used to define the cut-offs of DAl latencies as shown (Fig. S2). PC1 of DAI latencies explained $88 \%$ of DAI latency variance, while the PC1 of the restraining test explained $62 \%$ of the restraining test variance, with $75 \%$ of the overall behavioural variation being retained in these two components. Fish tested from different batch and strain showed parallel cut-offs for DAI latency (Fig. S2). The consistency over time and across behavioural paradigms of behavioural responses is shown in Table 2 and illustrated in Fig. S2. Interestingly, mostly of the variables were significantly correlated with DAI latency 
corroborating the use of this variable to separate the groups. Principal component analysis collapsing all behavioural parameters measured is represented in Fig. 1. The groups exhibited, "driven" by DAI latency, reveal that this behaviour is a robust predictor of distinctive personality groups, as PC1 explained $34 \%$ of such grouping. Behavioural variation unsurprisingly was significant across situations. Nevertheless, $50 \%$ of the grouping was explained by the two first dimensions of the PCA showing that personality is well represented in the behavioural phenotypes. Individual variation of each personality trait regarding each of the behavioural paradigms tested is shown in Table S1. Three groups were generated using determined DAI latencies cut-offs (proactive $n=30$; intermediate $n=27$; reactive $n=26$ ) identifying a balanced population of personality traits based on swimming activity, ventilation frequency, repeated DAl events and the three variables taken from the restraining test. One of the clusters (which we categorized as proactive individuals) took less time to restart feeding (One-way ANOVA; post hoc Fisher LSD $p=0.04 ; p<0.001$ ) and had a lower number of opercular beats after being deployed in the new environment (post hoc Fisher LSD $p=0.02 ; p<0.001$ ) when compared with the other 2 clusters (intermediate and reactive, respectively). When compared with reactive individuals, proactive fish showed increased escape behaviour (post hoc Fisher LSD $p<0.001$ ), increased swimming and exhibited lower levels of thygmotaxis (post hoc Fisher LSD $p=0.02$ ). Differences between personality groups under the different behavioural tests are shown in Fig. 2. No differences in initial body weight, coefficient of variation of initial body weights and total biomass were observed between individuals $\left(F_{(2,71)}=1.215 ; p=\right.$ 0.303).

Thermal restriction $\left(T_{R}\right)$ vs. thermal choice $\left(T_{C H}\right)$ : acute thermal period

Changes in acute thermal preference for each group during the first hour was assessed by counting the number of fish in each chamber at each minute ( $n=60$ events). The provision of thermal choice $\left(T_{C H}\right)$ induced an immediate and significant change highlighting preference for the warmest chambers (chamber 4: T $=29.86 \pm 0.02 \stackrel{\circ}{\circ}$ and chamber 5: $33.08 \pm 0.02 \stackrel{\circ}{\circ})$ in comparison to $T_{R}$ conditions (Wald $\chi_{(4,1497)}^{2}=148.447 p<$ 0.001; interaction Chamber x Condition). Distribution under thermal restriction $\left(T_{R}\right)$ condition was chamber dependent $\left(\right.$ Wald $\left.\chi_{(4,897)}^{2}=142.93, p<0.001\right)$ for all groups tested, indicating that in the absence of a gradient fish remain in the chamber they are introduced into. Comparing $T_{R}$ and $T_{C H}$ control groups, latency to exit and number of transitions between chambers shows that fish became more exploratory when in a thermal

This article is protected by copyright. All rights reserved. 
gradient, with lower latency for chamber transitions and a higher number of transitions between chambers $\left(F_{(1,3)}=9.092, p<0.001\right.$ and $F_{(1,3)}=193.727, p=0.02$ respectively $)$.

For different personalities distributions across chambers under $\mathrm{T}_{\mathrm{CH}}$ were not significantly different $\left(\right.$ Wald $\left.\chi_{(2,2698)}^{2}=16.996, p=0.590\right)$, however significantly different acute thermal preference were observed (Kruskal-Wallis $\left.\chi_{(2,539)}^{2}=7.675, p=0.022\right)$. This is shown as the mean of the individuals at each time point $(n=$ 60) for each chamber temperature (formula [1]). It is worth noting that this latter difference is strongly influenced by the thermal preference found for intermediates $(T=30.28 \pm 0.18 \stackrel{\circ}{\circ}$ ) that was lower than the measured proactive preference $(T=31.10 \pm 0.15 \stackrel{\circ}{\circ} \mathrm{C}$; Mann-Whitney, $\mathrm{U}=-2.579, \mathrm{p}=0.01)$. No differences were found between intermediate and reactive groups $(T=30.88 \pm 0.15 \stackrel{\circ}{ } \mathrm{C}$; Mann-Whitney, $\mathrm{U}=-1.854, \mathrm{p}=$ 0.06 ) or between proactive and reactive groups (Mann-Whitney, $U=-1.225, p=0.22$ ). Latency to exit and number of chamber transitions did not reveal any significant differences $\left(F_{(2,33)}=0.357 ; p=0.702 ; F_{(2,33)}=\right.$ $0.142 ; p=0.868)$ during the first hour of acclimation to the thermal gradient.

\section{Thermal preference and personality}

Analysis from the final thermal period showed that proactive, intermediate and reactive groups expressed significantly different final thermal preferences (Kruskal-Wallis, $\chi_{(2,296)}^{2}=40.779, p<0.001 ;$ Fig. 3a) with proactive fish displaying preference for higher temperatures (95\% confidence interval for median (31.1 $32 \stackrel{\circ}{\circ}$ ) mean $\mathrm{T}=31.32 \pm 0.18 \stackrel{\circ}{\circ}$ ) and reactive fish lower temperatures (95\% confidence interval for median (30.5 $-31 \stackrel{\circ}{\circ}$ ) mean $\mathrm{T}=30.37 \pm 0.14 \stackrel{\circ}{\circ}$ ). Interestingly, some intermediate individuals showed preference for

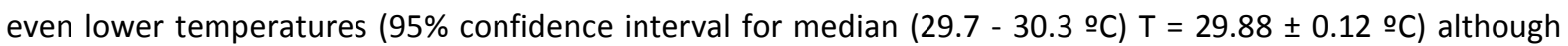
the pattern of distribution in the thermal gradient was similar to reactive groups (Wald $\chi_{(1,1485)}^{2}=3.466 p=$ 0.065 ) (Fig. 3b) and significantly different to proactive fish (Wald $\left.\chi_{(1,1485)}^{2}=8.292 ; p=0.004\right)$. Interestingly results show that naïve control groups under $\mathrm{T}_{\mathrm{CH}}$ conditions preferred temperatures above those experienced

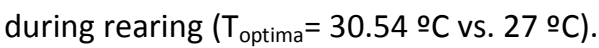

This article is protected by copyright. All rights reserved. 
Validation of thermal preference as a screening paradigm

Without any previous behavioural screening 8 groups of naïve individuals $(n=64)$, were tested under $\mathrm{T}_{C H}$ conditions. The population distribution in the last $8 \mathrm{~h}$ over $48 \mathrm{~h}$ test was significantly higher for chamber 4 as previously observed $\left(T=31.19 \pm 0.07\right.$ ㅇ $\mathrm{C}$ ( Wald $\left.\chi_{(4,1277)}^{2}=26.781 ; \mathrm{p}<0.001\right)$ (Fig. 4A). A posteriori behavioural screening of this population identified that $70 \%$ of the fish found in $31.19 \pm 0.07 \stackrel{\circ}{\circ}-33.59 \pm 0.10 \stackrel{\circ}{ }$ exhibited proactive traits. Intermediate and reactive individuals were identified in chambers with temperatures ranging between $27.80 \pm 0.07 \stackrel{\circ}{\circ}-29.74 \pm 0.05 \stackrel{\circ}{ }$ (Fig. 4B). In parallel 3 control groups with 8 naïve fish were tested in the $T_{R}$ environment $(T=26.58 \pm 0.35 \stackrel{\circ}{\circ})$ to evaluate the possibility of chamber preference independent from temperature. A homogeneous distribution was observed throughout the tank (Wald $\left.\chi_{(1,475)}^{2}=65.933 p>0.05\right)$ with no significant differences in preference.

\section{Behavioural fever in animal personalities}

Using a previously established $S$. iniae infection model we tested the behavioural fever response (under $\mathrm{T}_{\mathrm{CH}}$ conditions) of proactive, reactive and randomly selected individuals using an intra-peritoneal route of infection (Table 1, Fig. 5). Throughout the 5 days of bacterial challenge no abnormal swimming behaviour was observed in any experimental group. Control, i.p. injected with PBS $0.1 \%$, individuals did not present any mortality throughout the experimentation. In the proactive group mortalities were observed with 3 dead fish at 2 days post-infection and in reactive fish a single mortality was recorded at 1 day post-infection. In the first hour of acclimation to the $T_{C H}$ conditions differences in thermal preference were found between the groups tested (proactive $\mathrm{T}=27.95 \pm 0.05 \stackrel{\circ}{\circ} \mathrm{C}$; reactive $\mathrm{T}=29.17 \pm 0.18 \stackrel{\circ}{\circ} \mathrm{C}$; control $\mathrm{T}=31.94 \pm 0.58 \stackrel{\circ}{\circ}$; Kruskal-Wallis $\left.\chi_{(2,179)}^{2}=129.6, p<0.001\right)$ with both personality groups showing a decrease in acute thermal preference. At 24 $\mathrm{h}$ post infection, a behavioural fever response was evident for both groups with reactive individuals showing a significantly altered temperature preference (proactive $\mathrm{T}=31.75 \pm 0.25 \stackrel{\circ}{ } \mathrm{C}$; reactive $\mathrm{T}=32.94 \pm 0.06 \stackrel{\circ}{\circ}$; MannWhitney, $U=43.50 ; p<0.001$ ). Over the next 48 hours both groups showed a decrease in thermal preference with no significant difference between thermal preferences for the personality groups and the control group (proactive $\mathrm{T}=30.63 \pm 0.23 \stackrel{\circ}{\circ}$; reactive $\mathrm{T}=30.88 \pm 0.28 \stackrel{\circ}{ } \mathrm{C}$; control $\mathrm{T}=30.73 \pm 0.24 \stackrel{\circ}{ } \mathrm{C}$; Kruskal-Wallis $\chi_{(2,98)}^{2}=$ $1.800, p=0.407)$. However at $4-5$ days thermal preference returned to the previously measured final thermal 
preference of each group (Fig. 5: proactive: Wilcoxon rank test: $Z=-3.510 ; p<0.001 ; T=31.13 \pm 0.10 \stackrel{\circ}{ }$; reactive: $Z=-4.621 ; p<0.001 ; T=30.03 \pm 0.12 \stackrel{\circ}{\circ}$; control: $Z=-5.012 ; p<0.001 ; T=29.36 \pm 0.16 \stackrel{\circ}{\circ})$ ).

\section{Discussion}

The linkage between thermal preference and animal personality is a relatively new research paradigm. To the best of our knowledge few studies have used similar approaches to assess personality in fish (Killen 2014; Rey, Digka \& MacKenzie 2015) or other vertebrate species. In Tilapia housed in a freely accessible thermal gradient, spanning approximately $12^{\circ} \mathrm{C}$, proactive individuals showed preference for higher temperatures, as compared with reactive individuals. Testing was carried out by both pre-screening the fish for animal personality prior to thermal preference testing and vice versa. To mimic natural conditions, fish should be capable to express their full behavioural repertoire under artificial environments. Giving control or some sense or control can provide to fish the opportunity to activate proper coping mechanisms and minimize the effect of a punishment avoidance situation (normally the effect of standard behavioural paradigms to screen fish) e.g. by escaping, avoiding, moving or defend themselves against it. This allowed us to accurately validate the potential of thermal preference as an indicator of animal personality in mobile aquatic ectotherms. Additional experiments using bacterial infection further highlighted the importance of thermal choice at an individual level. Our results are of significant importance to understand the adaptive meaning of animal personality regarding ecological performance within a population.

Driven by the statement of Bell et al. (2009) in which biologically meaningful variability is conditioned by consistency of individual patterns, we demonstrate the repeatability of individual patterns over time (DAl 1 and $\mathrm{DAl}_{2}$ ) and across different situations. Our results show divergent personality traits within our population with proactive individuals being characterized by a faster feed intake recovery after transfer into a novel environment, lower breathing frequency and being more prone to escape from restraining, as compared with reactive individuals. The existence of "intermediate" individuals is common when working with domestic species due to low environmental challenge (Boersma 2011). Despite the extensive range of behavioural methodologies used, different suites of personality traits have been observed in many animal species (Réale et al 2007, Briffa et al 2013, Montiglio et al, 2014) and multiple fish species including the olive flounder, Paralichthys olivaceus (Rupia et al, 2016), Mulloway Argyrossomus japonicas (Raoult et al. 2012), Gilthead

This article is protected by copyright. All rights reserved. 
Seabream Sparus aurata (Herrera et al. 2014), Senegalense sole Solea senegalensis (Castanheira et al. 2011; Martins et al. 2011), European seabass Dicentrarchus labrax (Killen et al. 2012) and Zebrafish Danio rerio (Rey, Digka \& MacKenzie 2015). In the case of Tilapia the strong correlations between DAl and personality highlight the usefulness of Duration of Appetite Inhibition as a screening tool for boldness. Our results also support the use of Ventilation frequency (VF) as an indicator of behavioural-physiological traits by showing that VF is a good tool for predicting feeding behaviour in the same context. The same positive correlation between VF and DAI were also found by Barreto \& Volpato (2011). In summary, such behavioural responses have also been described in other fish species (Overli et al. 2002; MacKenzie et al. 2009; Silva et al. 2010; Martins et al. 2011) corroborating the idea that by choosing and tailoring behavioural tests different behavioural profiles can be accurately identified.

Acute thermal period

Fish exhibited significantly different distributions over $T_{R}$ and $T_{C H}$ in agreement with our predictions based around previous observations in zebrafish (Rey, Digka \& MacKenzie 2015). Fish were able to see between chambers and in the absence of an environmental motivation such as a thermal gradient $\left(T_{R}\right)$ fish displayed strong shoaling behaviour. An environmental enrichment, such as the gravel on the bottom of the tank, might have made individuals inhibit threat-sensitive behaviour such as exploration, risk taking or foraging and to reduce stress (Galhardo, Correia \& Oliveira 2008). In contrast under $T_{C H}$ conditions control fish distribution was strongly affected and the thermal gradient stimulated increased exploratory activity between chambers. Thus the fish are able to detect environmental thermal variation that could be linked to how individual animals appraise such changes (Martins, Conceição \& Schrama 2011b). Perception of positive environmental factors combined with the possibility to control phenotypically such environmental condition (e.g. by swimming through the experimental tank) is known to have a positive impact on animal welfare (Greiveldinger, Veissier \& Boissy 2009). The change in swimming patterns and distribution over the first hour of test might be the result of a trade-off between the costs and benefits associated with thermoregulation (Shine \& Madsen 1996). Differences in swimming activity regarding exploration have previously been reported (Careau et al. 2008) as an intrinsic pattern of personality traits in several animal species (Reale et al. 2007). Several findings have shown that individual metabolic patterns may be related to different behavioural traits in animals (Biro \& Stamps 2008; Careau et al. 2008; Herrera et al. 2014). This behavioural and physiological

This article is protected by copyright. All rights reserved. 
covariation has been previously hypothesised in which personality types mirror variation in metabolic patterns (Biro \& Stamps 2010; Careau \& Garland 2012; Metcalfe, Van Leeuwen \& Killen 2015). Alternatively the impact of the effects of stress on thermal preference due to emotional fever could also explain the change in fish distribution with naïve animals experiencing higher stress responses to the novel tank environment (Rey et al. 2015).

Temperature preference predicts personality - final thermal period

As stated by Jobling (1981) if given enough time fish will congregate at the final thermal preferendum, which is deemed to correspond to the $\mathrm{T}_{\mathrm{optima}}$ at which fish growth fast. In Nile Tilapia the reported $\mathrm{T}_{\text {optima }}$ is of 27-33 ${ }^{\circ} \mathrm{C}$ (Azaza, Dhraïef \& Kraïem 2008; Azaza et al. 2010). Our results agree with this thermal range corresponding to the final thermal preferendum (Fry 1947). When fish were screened posteriorly for personality our results confirmed an increased final thermal preference in proactive fish in comparison to both other groups tested. Therefore thermal preference can be used as a physiological paradigm to screen fish for personality and provides an important insight into individual variation. Our results are in agreement with previous studies in zebrafish (Rey, Digka \& MacKenzie 2015). Thus, the higher end of temperature preference for the species may reflect increased energetic requirements in proactive individuals with a higher metabolic engine. Interestingly, Blackmer et al. (2005) suggested that increased energy requirements in proactive individuals is compensated by swimming behaviour i.e. displacement to warmer places, another component of the energetic repertoire. Such association between metabolic rate and behaviour leading to elevated energy expression in proactive individuals has been previously reported (Careau et al. 2008; Biro \& Stamps 2010). Despite the apparently small difference between thermal preferences for each personality type (about $1 \stackrel{\circ}{ }$ ), it has a relevant ecological impact as metabolic rates from proactive individuals increase by $>10 \%$ (Clarke \& Johnston 1999) when compared to reactive conspecifics. Thermal preference could be seen as a coadaptation of natural selection being partially explained as a trade-off between inherited behavioural predispositions and physiological demands (Korte et al. 2005). Thus in mobile ectotherms including fish, we propose that thermal preference is correlated to animal personality and understanding how individuals use thermal gradients will aid in our understanding of how individuals in a population optimize and adapt performance and fitness in different environmental scenarios.

This article is protected by copyright. All rights reserved. 


\section{Behavioural fever in animal personalities}

Under infection, proactive and reactive individuals showed similar thermal strategies to combat bacterial invasion (Fig. 5). These results extend previous observations describing the impact of thermal choice upon the immune response (Boltana et al. 2013). The implications of animal personality and thermal choice in response to Streptococcus iniae infections in Nile tilapia have not been previously reported. Streptococcus iniae is a significant pathogen globally affecting Nile Tilapia aquaculture (Eldar et al. 1997; Shoemaker, Klesius \& Evans 2001) and has been shown to positively correlate with increased environmental temperature (Bromage \& Owens 2009). Behavioural fever is defined as an acute change in thermal preference driven by pathogen recognition and referred as a synergic signal to improve the immune response of fish (Boltana et al. 2013). To our knowledge these are the first experiments reporting upon the relationship between bacterial infection, behavioural fever and personality in mobile ectotherms. Behavioural fever induced by bacterial infection was originally reported in carp (Reynolds, Casterlin \& Covert 1976) and few studies have followed upon these original findings. In this experiment we show that infection induces behavioural fever in all fish that were challenged highlighted by the peak thermal response at $24 \mathrm{~h}$ post-infection. Initial measures at $1 \mathrm{~h}$ postintra-peritoneal injection highlight differential stress responses where naïve control fish display a strong emotional fever response (Rey, Digka \& MacKenzie 2015). In the other experimental groups this response is not observed likely due to previous habituation to handling during behavioural phenotyping and thermal screening in the gradient environment. Of particular interest is the observation that the host response to infection overrides personality-driven thermal preferences until the infection is cleared. In this experiment no mortalities were observed after $48 \mathrm{~h}$ of infection. At 4 days post-infection thermal preferenda were restored as predicted by personality. As stated by Frost et al. (2013), natural environments often inflict abiotic challenges on populations. With the threat of climate change and diverse anthropogenic influences, the study of the physiological traits here highlighted by host-pathogen interaction in which thermal choice influences performance, understanding individual response within a population framework becomes critical to predict impact and survival.

\section{Data Accessibility}

Data are available on Figshare: http://dx.doi.org/10.6084/m9.figshare.3114967 (MacKenzie 2016).

This article is protected by copyright. All rights reserved. 


\section{Acknowledgments}

The access to Institute of Aquaculture, University of Stirling was funded by the European Union's Seventh Framework Programme (FP7/2007-2013) under grant agreement $n^{\circ}$ 262336, AQUAEXCEL. M. Cerqueira PhD contract (SFRH/BD/80029/2011) was supported by Fundação para a Ciência e Tecnologia (Portugal). The authors are grateful to the technical staff at the Institute of Aquaculture aquaria for their invaluable help. The procedures described in this paper comply with animal care guidelines approved by the Home Office, UK.

\section{References}

Angilletta Jr, M.J., Niewiarowski, P.H. \& Navas, C.A. (2002) The evolution of thermal physiology in ectotherms. Journal of Thermal Biology, 27, 249-268.

Azaza, M.S., Dhraïef, M.N. \& Kraïem, M.M. (2008) Effects of water temperature on growth and sex ratio of juvenile Nile tilapia Oreochromis niloticus (Linnaeus) reared in geothermal waters in southern Tunisia. Journal of Thermal Biology, 33, 98-105.

Azaza, M.S., Legendre, M., Kraiem, M.M. \& Baras, E. (2010) Size-dependent effects of daily thermal fluctuations on the growth and size heterogeneity of Nile tilapia Oreochromis niloticus. Journal of Fish Biology, 76, 669-683.

Barreto, R.E. \& Volpato, G.L. (2011) Ventilation rates indicate stress-coping styles in Nile tilapia. Journal of Biosciences, 36, 851-855.

Barreto, R.E., Volpato, G.L., de Brito Faturi, C., Giaquinto, P.C., Gonçalves de Freitas, E. \& Fernandes de Castilho, M. (2009) Aggressive behaviour traits predict physiological stress responses in Nile tilapia (Oreochromis niloticus). Marine and Freshwater Behaviour and Physiology, 42, 109-118.

Bell, A.V., Rader, R.B., Peck, S.L. \& Sih, A. (2009) The positive effects of negative interactions: Can avoidance of competitors or predators increase resource sampling by prey? Theoretical Population Biology, 76, 5258.

Biro, P.A., Beckmann, C. \& Stamps, J.A. (2009) Small within-day increases in temperature affects boldness and alters personality in coral reef fish. Proceedings of the Royal Society of London B: Biological Sciences, 277, 71-77.

This article is protected by copyright. All rights reserved. 
Biro, P.A. \& Dingemanse, N.J. (2009) Sampling bias resulting from animal personality. Trends Ecol Evol, 24, 6667.

Biro, P.A. \& Stamps, J.A. (2008) Are animal personality traits linked to life-history productivity? Trends in Ecology \& Evolution, 23, 361-368.

Biro, P.A. \& Stamps, J.A. (2010) Do consistent individual differences in metabolic rate promote consistent individual differences in behavior? Trends Ecol Evol, 25, 653-659.

Blackmer, A.L., Mauck, R.A., Ackerman, J.T., Huntington, C.E., Nevitt, G.A. \& Williams, J.B. (2005) Exploring individual quality: basal metabolic rate and reproductive performance in storm-petrels. Behavioral Ecology, 16, 906-913.

Boersma, G.J. (2011) Coping styles and the pathophysiology of energy metabolism. University of Groningen the Netherlands, 240 p.

Boltana, S., Rey, P.S., Roher, N., Vargas, R., Huerta, M., Huntingford, F.A., Goetz, F.W., Moore, J., GarciaValtanen, P., Estepa, A. \& MacKenzie, S. (2013) Behavioural fever is a synergic signal amplifying the innate immune response. Proceedings of the Royal Society B: Biological Sciences, 280.

Briffa, M., Bridger, D., Biro, P.A., 2013. How does temperature affect behaviour? Multilevel analysis of plasticity, personality and predictability in hermit crabs. Animal Behaviour 86, 47-54

Bromage, E. \& Owens, L. (2009) Environmental factors affecting the susceptibility of barramundi to Streptococcus iniae. Aquaculture, 290, 224-228.

Careau, V. \& Garland, T., Jr. (2012) Performance, personality, and energetics: correlation, causation, and mechanism. Physiol Biochem Zool, 85, 543-571.

Careau, V., Thomas, D., Humphries, M.M. \& Réale, D. (2008) Energy metabolism and animal personality. OIKOS, 117, 641-653.

Castanheira, M.F., Conceição, L.E.C., Millot, S., Rey, S., Bégout, M.-L., Damsgård, B., Kristiansen, T., Höglund, E., $\varnothing$ verli, Ø. \& Martins, C.I.M. (2015) Coping styles in farmed fish: consequences for aquaculture. Reviews in Aquaculture, n/a-n/a.

Castanheira, M.F., Herrera, M., Costas, B., Conceição, L.E.C. \& Martins, C.I.M. (2013a) Can We Predict Personality in Fish? Searching for Consistency over Time and across Contexts. PLOS ONE, 8, e62037.

This article is protected by copyright. All rights reserved. 
Castanheira, M.F., Herrera, M., Costas, B., Conceição, L.E.C. \& Martins, C.I.M. (2013b) Linking cortisol responsiveness and aggressive behaviour in gilthead seabream Sparus aurata: Indication of divergent coping styles. Applied Animal Behaviour Science, 143, 75-81.

Castanheira, M.F., Martins, C.I.M., Engrola, S. \& Conceição, L.E.C. (2011) Daily oxygen consumption rhythms of Senegalese sole solea senegalensis (Kaup, 1858) juveniles. Journal of Experimental Marine Biology and Ecology, 407, 1-5.

Clarke A, Fraser KPP., (2004). Why does metabolism scale with temperature? Func Ecol 2004; 18, $243-251$.

Clarke, A. \& Johnston, N.M. (1999) Scaling of metabolic rate with body mass and temperature in teleost fish. Journal of Animal Ecology, 68, 893-905.

Cleasby, I.R. \& Nakagawa, S. (2011) Neglected biological patterns in the residuals A behavioural ecologist's guide to co-operating with heteroscedasticity. Behavioral Ecology and Sociobiology, 65, 2361-2372.

Dingemanse, N.J., Kazem, A.J.N., Réale, D. \& Wright, J. (2010) Behavioural reaction norms: animal personality meets individual plasticity. Trends in Ecology \&amp; Evolution, 25, 81-89.

Eldar, A., Lawhon, S., Frelier, P.F., Assenta, L., Simpson, B.R., Varner, P.W. \& Bercovier, H. (1997) Restriction fragment length polymorphisms of $16 \mathrm{~S}$ rDNA and of whole rRNA genes (ribotyping) of Streptococcus iniae strains from the United States and Israel. FEMS Microbiol Lett, 151, 155-162.

Featherstone, Z.L., Turnbull, J.F., Auchinachie, N.A. \& Crumlish, M., (2015). Evaluation of visible implant elastomer tags for pathogenesis research in Nile tilapia (Oreochromis niloticus). Aquaculture Research, doi: $10.1111 /$ are.12688.

Fevolden, S.-E., Røed, K.H. \& Fjalestad, K.T. (2002) Selection response of cortisol and lysozyme in rainbow trout and correlation to growth. Aquaculture, 205, 61-75.

Finstad, A.G., Forseth, T., Ugedal, O. \& NESSe, T.F. (2007) Metabolic rate, behaviour and winter performance in juvenile Atlantic salmon. Functional Ecology, 21, 905-912.

Frerichs, G.N., and Millar, S.D. (1993) Manual for the Isolation and Identification of Fish Bacterial Pathogens. Pisces Press, Stirling, U.K.

Frost, A.J., Thomson, J.S., Smith, C., Burton, H.C., Davis, B., Watts, P.C. \& Sneddon, L.U. (2013) Environmental change alters personality in the rainbow trout, Oncorhynchus mykiss. Animal Behaviour, 85, 11991207.

This article is protected by copyright. All rights reserved. 
Fry, F.E.J. (1947) Effects of the environment on animal activity. Biological Series $n$. 55, pp. 1-62. University of Toronto, Ontario Fish. Res. Lab.

Galhardo, L., Correia, J. \& Oliveira, R.F. (2008) The effect of substrate availability on behavioural and physiological indicators of welfare in the African cichlid (Oreochromis mossambicus). Animal Welfare, $17,239-254$.

Greiveldinger, L., Veissier, I. \& Boissy, A. (2009) Behavioural and physiological responses of lambs to controllable vs. uncontrollable aversive events. Psychoneuroendocrinology, 34, 805-814.

Herrera, M., Castanheira, M.F., Conceição, L.E.C. \& Martins, C.I. (2014) Linking risk taking and the behavioral and metabolic responses to confinement stress in gilthead seabream Sparus aurata. Applied Animal Behaviour Science, 155, 101-108.

Huey, R.B. \& Bennett, A.F. (1987) Phylogenetic Studies of Coadaptation: Preferred Temperatures Versus Optimal Performance Temperatures of Lizards. Evolution, 41, 1098-1115.

Huey, R.B. \& Kingsolver, J.G. (1989) Evolution of thermal sensitivity of ectotherm performance. Trends in Ecology \& Evolution, 4, 131-135.

Huntingford, F.A., Andrew, G., Mackenzie, S., Morera, D., Coyle, S.M., Pilarczyk, M. \& Kadri, S. (2010) Coping strategies in a strongly schooling fish, the common carp Cyprinus carpio. J Fish Biol, 76, 1576-1591.

Jobling, M. (1981) Temperature tolerance and the final preferendum-rapid methods for the assessment of optimum growth temperatures. Journal of Fish Biology, 19, 439-455.

Killen, S.S. (2014) Growth trajectory influences temperature preference in fish through an effect on metabolic rate. Journal of Animal Ecology, 83, 1513-1522.

Killen, S.S., Marras, S., Ryan, M.R., Domenici, P. \& McKenzie, D.J. (2012) A relationship between metabolic rate and risk-taking behaviour is revealed during hypoxia in juvenile European sea bass. Functional Ecology, 26, 134-143.

Klein M., Afonso B., Vonner A.J., Hernandez-Nunez L., Berck M., Tabone C.J., Kane E.A., Pieribone V.A., Nitabach M.N., Cardona A., Zlatic M.,Sprecher S.G., Gershow M., Garrity P.A., Samuel A.D.. (2014) Sensory determinants of behavioral dynamics in Drosophila thermotaxis. Proceedings of the National Academy of Sciences of the United States of America 112, E220-229.

This article is protected by copyright. All rights reserved. 
Korte, S.M., Koolhaas, J.M., Wingfield, J.C. \& McEwen, B.S. (2005) The Darwinian concept of stress: benefits of allostasis and costs of allostatic load and the trade-offs in health and disease. Neurosci Biobehav Rev, 29, 3-38.

MacKenzie, S., Ribas, L., Pilarczyk, M., Capdevila, D.M., Kadri, S. \& Huntingford, F.A. (2009) Screening for Coping Style Increases the Power of Gene Expression Studies. PLOS ONE, 4, e5314.

MacKenzie, S (2016): Thermal preference predicts animal personality in Nile tilapia Oreochromis niloticus data. figshare. https://dx.doi.org/10.6084/m9.figshare.3114967.v2

Martins, C.I.M., Castanheira, M.F., Engrola, S., Costas, B. \& Conceição, L.E.C. (2011) Individual differences in metabolism predict coping styles in fish. Applied Animal Behaviour Science, 130, 135-143.

Martins, C.I.M., Conceição, L.E.C. \& Schrama, J.W. (2011a) Consistency of individual variation in feeding behaviour and its relationship with performance traits in Nile tilapia Oreochromis niloticus. Applied Animal Behaviour Science, 133, 109-116.

Martins, C.I.M., Conceição, L.E.C. \& Schrama, J.W. (2011b) Feeding behavior and stress response explain individual differences in feed efficiency in juveniles of Nile tilapia Oreochromis niloticus. Aquaculture, 312, 192-197.

Metcalfe, N.B., Van Leeuwen, T.E. \& Killen, S.S. (2015) Does individual variation in metabolic phenotype predict fish behaviour and performance? Journal of Fish Biology, n/a-n/a.

Miles, A.A., Misra, S.S. \& Irwin, J.O. (1938) The estimation of the bactericidal power of the blood. The Journal of Hygiene, 38, 732-749.

Montiglio P.O., Garant D., Bergeron P., Messier G.D., Réale D., 2014. Pulsed resources and the coupling between life-history strategies and exploration patterns in eastern chipmunks (Tamias striatus). J Anim Ecol. May;83(3):720-8.

Overli, O., Pottinger, T.G., Carrick, T.R., Overli, E. \& Winberg, S. (2002) Differences in behaviour between rainbow trout selected for high- and low-stress responsiveness. J Exp Biol, 205, 391-395.

Overli, O., Sorensen, C., Pulman, K.G.T., Pottinger, T.G., Korzan, W., Summers, C.H. \& Nilsson, G.E. (2007) Evolutionary background for stress-coping styles: relationships between physiological, behavioral, and cognitive traits in non-mammalian vertebrates. Neuroscience and Biobehavioral Reviews, 31, 396-412.

This article is protected by copyright. All rights reserved. 
Pawson, M.G., Pickett, G.D. \& Witthames, P.R. (2000) The influence of temperature on the onset of first maturity in sea bass. Journal of Fish Biology, 56, 319-327.

Raoult, V., Brown, C., Zuberi, A. \& Williamson, J. (2012) Blood cortisol concentrations predict boldness in juvenile mulloway (Argyosomus japonicus). Journal of Ethology, 30, 225.

Reale, D., Reader, S.M., Sol, D., McDougall, P.T. \& Dingemanse, N.J. (2007) Integrating animal temperament within ecology and evolution. Biol Rev Camb Philos Soc, 82, 291-318.

Rey, S., Boltana, S., Vargas, R., Roher, N. \& Mackenzie, S. (2013) Combining animal personalities with transcriptomics resolves individual variation within a wild-type zebrafish population and identifies underpinning molecular differences in brain function. Mol Ecol, 22, 6100-6115.

Rey, S., Digka, N. \& MacKenzie, S. (2015) Animal Personality Relates to Thermal Preference in Wild-Type Zebrafish, Danio rerio. Zebrafish, 12, 243-249.

Rey S, Huntingford FA, Boltaña S, Vargas R, Knowles TG, Mackenzie S.(2015) Fish can show emotional fever: stress induced hyperthermia in zebrafish. Proc Biol Sci. Nov 22;282(1819).

Reynolds, W.W., Casterlin, M.E. \& Covert, J.B. (1976) Behavioural fever in teleost fishes. Nature, 259, 41-42.

Rupia E.J., Binning S.A., Roche D.G., Lu W. (2016). Fight-flight or freeze-hide? Personality and metabolic phenotype mediate physiological defence responses in flatfish. J Anim Ecol. Apr 5., doi: 10.1111/13652656.12524

Shine, R. \& Madsen, T. (1996) Is Thermoregulation Unimportant for Most Reptiles? An Example Using Water Pythons (Liasis fuscus) in Tropical Australia. Physiological Zoology, 69, 252-269.

Shoemaker, C.A., Klesius, P.H. \& Evans, J.J. (2001) Prevalence of Streptococcus iniae in tilapia, hybrid striped bass, and channel catfish on commercial fish farms in the United States. Am J Vet Res, 62, 174-177.

Sih, A., Bell, A. \& Johnson, J.C. (2004) Behavioral syndromes: an ecological and evolutionary overview. Trends in Ecology \& Evolution, 19, 372-378.

Silva, P.I.M., Martins, C.I.M., Engrola, S., Marino, G., Øverli, Ø. \& Conceição, L.E.C. (2010) Individual differences in cortisol levels and behaviour of Senegalese sole (Solea senegalensis) juveniles: Evidence for coping styles. Applied Animal Behaviour Science, 124, 75-81.

Somero, G.N., 2012. The Physiology of Global Change: Linking Patterns to Mechanisms. Annual Review of Marine Science 4, 39-61.

Stamps, J.A. (2007) Growth-mortality tradeoffs and 'personality traits' in animals. Ecology Letters, 10, 355-363.

This article is protected by copyright. All rights reserved. 
VeraCruz, E.M., Valdez, M.B., Bolivar, R.B. \& Borski, R.J. (2011) Duration of appetite inhibition predicts social dominance in Nile Tilapia (Oreochromis niloticus L.). Proceedings on the 9th International Symposium on Tilapia in Aquaculture, pp. 101-110. Aquafish, Shangai, China.

\section{Tables}

Table 1. Experimental infection groups used to test thermal preference of fish with different personality traits to an i.p. Infection with stablished S. iniae bacterial model.

Table 2. Consistency of behavioural responses over time (DAI1 and DAI2) and across different behavioural paradigms (VF; NE; DAI (DAI latency; lat2move; FI) from both events (DAI1 and DAI2); NR (total escapes; time escape and lat2escape) in Nile Tilapia, depicted by Pearson correlation ( $r$ ).

\section{Figures}

Fig. 1. Principal component analysis collapsing all behavioural parameters measured within the behavioural paradigms (swimming activity from NE; ventilation frequency from VF, DAl latency, time2move and FI from both $\mathrm{DAI}_{1}$ and $\mathrm{DAl}_{2}$; and the three variables taken from the NR [total escapes; time escape and lat2escape]). Fish are classified using pre-determined DAl latency cut-offs. Both first and second component scores explained $50 \%$ of the variance.

Fig. 2. Distinct clustered groups $(P$ - proactive $(n=30), I-$ intermediate $(n=27)$ and $R$ - reactive $(n=26))$ generated after $\mathrm{DAl}_{1}$ and $\mathrm{DAl}_{2}$ latency measurements: a) Restraining $\left(\mathrm{F}_{(2,80)}=7.02, \mathrm{p}=0.001\right)$; Individuals with low restraining scores escaped less during net restraining. b) PC1 DAI $\left.{ }_{1}\left(F_{(2,80)}=13.87, p<0.001\right) ; c\right) P C 1 D^{2} I_{2}$ $\left(F_{(2,80)}=15.22, p<0.001\right)$; Individuals with lower DAl scores took longer to restart feeding. d) VF: \# opercula beats $\min ^{-1}\left(F_{(2,80)}=7.40, p=0.001\right)$; Individuals with reactive traits showed higher number of opercula beats. e) NE: Swimming Activity \% $\left(\mathrm{F}_{(2,80)}=2.67, \mathrm{p}=0.07\right)$; Reactive individuals showed lower swimming activity levels. Fisher LSD post hoc is indicated by differing letters $(p<0.05)$.

This article is protected by copyright. All rights reserved. 
Fig. 3 a1) Nonlinear fit of fish, proactive, reactive and intermediate, distribution across the thermal gradient, a2) mean + SEM of each group after 48 hours, b) Final thermal preference for each of the personality group tested (mean \pm SEM: Proactive, $31.32 \pm 0.18 \stackrel{\circ}{\circ}$; Intermediate, $30.37 \pm 0.14 \stackrel{\circ}{\circ}$; Reactive, $29.88 \pm 0.12 \stackrel{\circ}{\circ}$ ); Different letters indicate significant pairwise differences (Mann-Whitney U; a,b: $p<0.05 ; a, c: p<0.05 ; b, c: p<$ $0.01)$

Fig. 4 a) -\% of individuals, no behavioural pre-screening, in groups of 8 individuals to the thermal gradient after $48 \mathrm{~h}(\mathrm{n}=64, \%$ mean \pm SEM), b) \% of individuals of each personality in each chamber, fish were screened for personality post-thermal distribution.

Fig. 5. Thermal preference $\left({ }^{0} \mathrm{C}\right)$ of S.iniae challenged individuals after the first hour of deployment postinfection (acute thermal period) and over the first 8 hours of each day throughout the trial (naïve fish (Ctr); reactive fish $(R)$ and proactive fish $(P)$. Final thermal period within infection period are shown between 48 and $72 \mathrm{~h}$ post-infection. Final thermal period regarding personality group preference is shown after $120 \mathrm{~h}$ postinfection.

Table 1.

\begin{tabular}{|c|c|c|}
\hline Treatment & Conditions & i.p. injection \\
\hline Naïve Control & $\mathrm{T}_{\mathrm{CH}}$ & PBS 0.1\% \\
\hline Reactive & $\mathrm{T}_{\mathrm{CH}}$ & S.iniae $2.97 \times 10^{\wedge} 7 \mathrm{cfu}$ per inoculum \\
\hline Proactive & $\mathrm{T}_{\mathrm{CH}}$ & S.iniae $2.35 \times 10^{\wedge} 7 \mathrm{cfu}$ per inoculum \\
\hline
\end{tabular}

This article is protected by copyright. All rights reserved. 
Table 2.

\begin{tabular}{|c|c|c|c|c|c|c|c|c|c|c|c|}
\hline & & VF & NE & $\begin{array}{c}\mathrm{DAl}_{1} \\
\text { lat }\end{array}$ & $\begin{array}{c}\text { lat2 } \\
\text { move1 }\end{array}$ & FI1 & $\begin{array}{c}\mathrm{DAl}_{2} \\
\text { lat }\end{array}$ & $\begin{array}{c}\text { lat2 } \\
\text { move }_{2}\end{array}$ & $\mathrm{FI}_{2}$ & $\begin{array}{l}\text { lat2 } \\
\text { escape }\end{array}$ & $\begin{array}{l}\text { time } \\
\text { escape }\end{array}$ \\
\hline \multirow{2}{*}{ NE } & $r$ & $-0,26$ & & $-0,28$ & 0,15 & 0,22 & $-0,17$ & 0,05 & 0,15 & $-0,04$ & 0,17 \\
\hline & $p$ & 0,018 & & 0,010 & 0,185 & 0,046 & 0,123 & 0,653 & 0,165 & 0,747 & 0,124 \\
\hline \multirow{2}{*}{$\mathrm{DAl}_{1}$ lat } & $r$ & 0,27 & $-0,28$ & & $-0,51$ & $-0,71$ & 0,35 & $-0,21$ & $-0,47$ & 0,16 & $-0,28$ \\
\hline & $p$ & 0,013 & 0,010 & & 0,000 & 0,000 & 0,001 & 0,054 & 0,000 & 0,158 & 0,011 \\
\hline \multirow{2}{*}{$\begin{array}{c}\text { lat2 } \\
\text { move }_{1}\end{array}$} & $r$ & $-0,09$ & 0,15 & $-0,51$ & & 0,60 & $-0,19$ & 0,13 & 0,23 & 0,01 & 0,06 \\
\hline & $p$ & 0,441 & 0,185 & 0,000 & & 0,000 & 0,080 & 0,226 & 0,039 & 0,919 & 0,564 \\
\hline \multirow{2}{*}{$\mathrm{Fl}_{1}$} & $r$ & $-0,19$ & 0,22 & $-0,71$ & 0,60 & & $-0,30$ & 0,16 & 0,42 & $-0,18$ & 0,33 \\
\hline & $p$ & 0,080 & 0,046 & 0,000 & 0,000 & & 0,006 & 0,156 & 0,000 & 0,097 & 0,002 \\
\hline \multirow{2}{*}{$\mathrm{DAl}_{2}$ lat } & $r$ & 0,37 & $-0,17$ & 0,35 & $-0,19$ & $-0,30$ & & $-0,59$ & $-0,71$ & 0,15 & $-0,22$ \\
\hline & $p$ & 0,001 & 0,123 & 0,001 & 0,080 & 0,006 & & 0,000 & 0,000 & 0,179 & 0,049 \\
\hline \multirow{2}{*}{$\begin{array}{c}\text { lat2 } \\
\text { move }_{2}\end{array}$} & $r$ & $-0,29$ & 0,05 & $-0,21$ & 0,13 & 0,16 & $-0,59$ & & 0,61 & $-0,18$ & 0,14 \\
\hline & $p$ & 0,008 & 0,653 & 0,054 & 0,226 & 0,156 & 0,000 & & 0,000 & 0,106 & 0,216 \\
\hline \multirow{2}{*}{$\mathrm{Fl}_{2}$} & $r$ & $-0,33$ & 0,15 & $-0,47$ & 0,23 & 0,42 & $-0,71$ & 0,61 & & $-0,17$ & 0,17 \\
\hline & $p$ & 0,002 & 0,165 & 0,000 & 0,039 & 0,000 & 0,000 & 0,000 & & 0,131 & 0,125 \\
\hline \multirow{2}{*}{$\begin{array}{c}\text { lat2 } \\
\text { escape }\end{array}$} & $r$ & $-0,04$ & $-0,04$ & 0,16 & 0,01 & $-0,18$ & 0,15 & $-0,18$ & $-0,17$ & & $-0,66$ \\
\hline & $p$ & 0,728 & 0,747 & 0,158 & 0,919 & 0,097 & 0,179 & 0,106 & 0,131 & & 0,000 \\
\hline \multirow{2}{*}{$\begin{array}{c}\text { time } \\
\text { escape }\end{array}$} & $r$ & $-0,19$ & 0,17 & $-0,28$ & 0,06 & 0,33 & $-0,22$ & 0,14 & 0,17 & $-0,66$ & \\
\hline & $p$ & 0,085 & 0,124 & 0,011 & 0,564 & 0,002 & 0,049 & 0,216 & 0,125 & 0,000 & \\
\hline \multirow{2}{*}{$\begin{array}{c}\text { total } \\
\text { escapes }\end{array}$} & $r$ & $-0,20$ & 0,27 & $-0,35$ & 0,11 & 0,36 & $-0,20$ & 0,11 & 0,27 & $-0,55$ & 0,72 \\
\hline & $p$ & 0,073 & 0,014 & 0,001 & 0,340 & 0,001 & 0,073 & 0,333 & 0,012 & 0,000 & 0,000 \\
\hline
\end{tabular}

\section{Supplementary Figures}

Fig.S1 Experimental multi-chamber tank used to test thermal preference of fish with different personality traits.

Fig.S2 Duration of Appetite Inhibition latencies (in seconds) distribution for 54 tilapia from a wild-type background and 94 tilapia with a Homo-Gold genetic background tested ( $x$ axis is fish running number and $y$ axis is time in seconds). Homo-Gold individual latency is represented here for illustrative reasons, by the means of $\mathrm{DAl}_{1}$ and $\mathrm{DAl}_{2}$ latencies. Fish that spend less than 300 seconds to eat were classified as proactives (Wild type $=36 \%$ and Homo-Gold $=39.4 \%$ ), between 300 and 600 seconds were intermediates and more than 600 seconds were reactives (Wild type $=49 \%$ and Homo-Gold $=29.8 \%$ ). Personality percentages plotted as a pie chart for both Wild-type and Homo-Gold.

This article is protected by copyright. All rights reserved. 
Fig. S3 Illustration of unsupervised K-means clustering and hierarchical clustering, using Ward's criterion, of the 3 groups segregated by DAI1 and DAI2 latencies, and the behaviours measured from NR collapsed into principal component scores. DAl latencies explained $82 \%$ of the fish dispersion, over 62 from the NR test. DAI latencies were chosen as behavioural measure to define the cut-off of the different personality groups. Both DAI latencies events were positively correlated (Pearson correlation $r=0.753, p<0.001$ ) and the cut-off thresholds were determined for each personality traits (proactive: $0<\mathrm{DAl}<300$; intermediate: $300<\mathrm{DAl}<$ 600; reactive: $\mathrm{DAI}>600 ; \mathrm{N}=96$ ). One-way ANOVA $\mathrm{F}(2,91)=124.33, \mathrm{p}<0.001$ (LSD post hoc: proactive vs intermediate, $\mathrm{p}<0.001$; proactive vs reactive, $\mathrm{p}<0.001$; reactive vs intermediate, $\mathrm{p}=0.009$ ).

Fig. S4 Correlogram with all the variables measured within the behavioural paradigms (VF; NE; DAI (DAI latency; lat2move; FI) from both events (DAI1 and DAI2); NR (total escapes; time escape and lat2escape). Color scheme represents Pearson correlation ( $r$ ) - values from -1 (blue) to 1 (red); Values indicate the $r$ correlation. Between brackets are presented the confident intervals of such $r$ (when confidence interval not crossing $0, p<$ $0.05)$.

Fig. S5 Establishment (1) and stabilization (2) of the thermal gradient within each chamber of the experimental

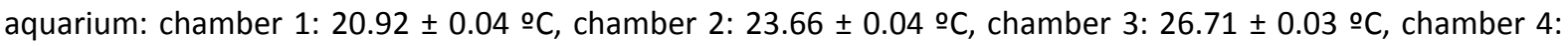
$29.86 \pm 0.02 \stackrel{\circ}{\circ}$, chamber $5: 33.08 \pm 0.02 \stackrel{\circ}{ } \mathrm{C}$.

This article is protected by copyright. All rights reserved. 
Figure 1

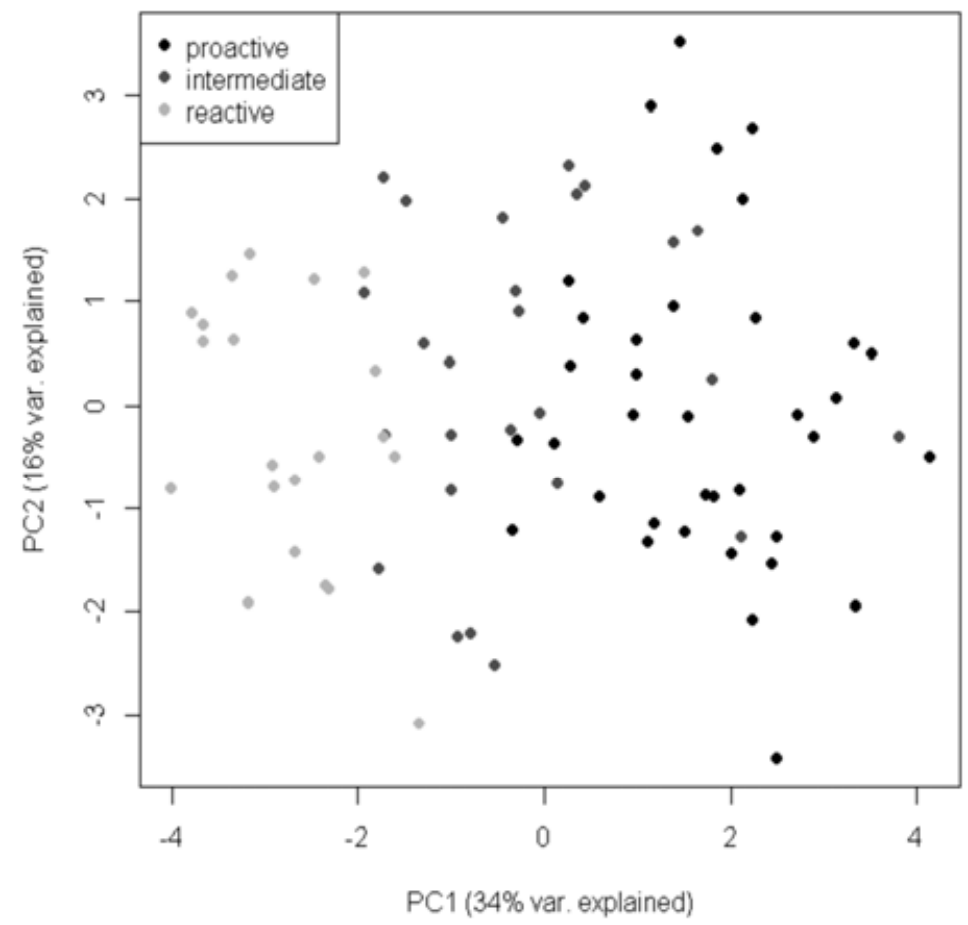

This article is protected by copyright. All rights reserved. 
Figure 2
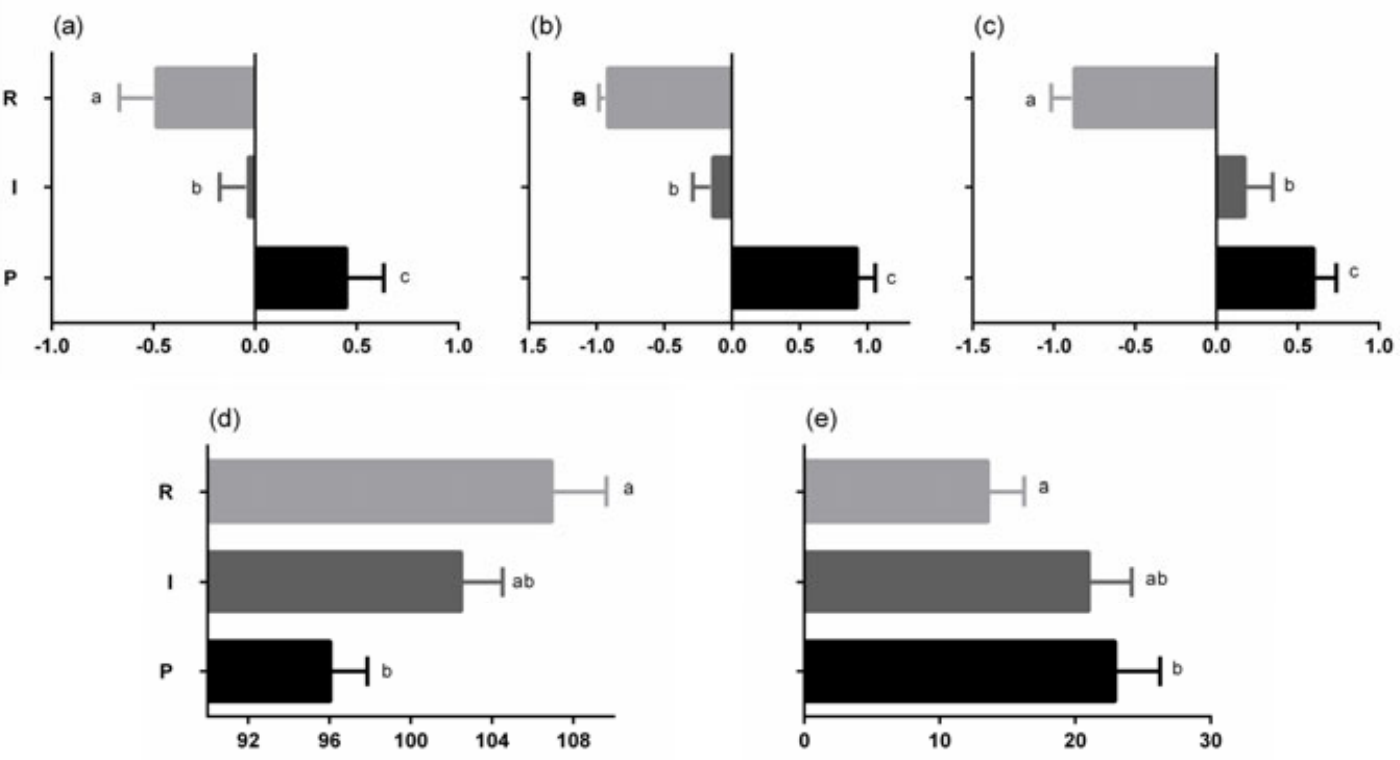

This article is protected by copyright. All rights reserved. 


\section{Figure 3}

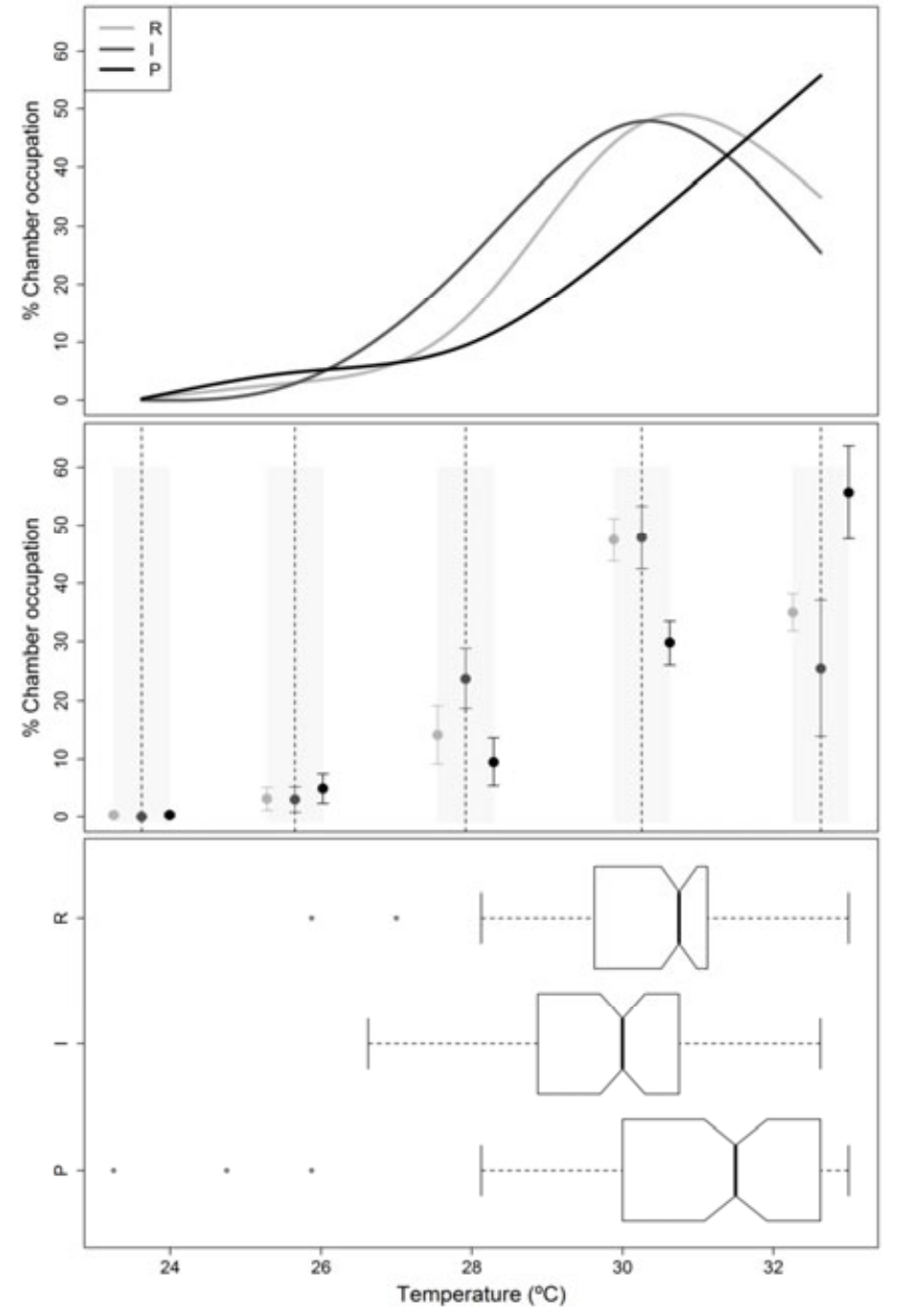

This article is protected by copyright. All rights reserved. 
Figure 4

(a)

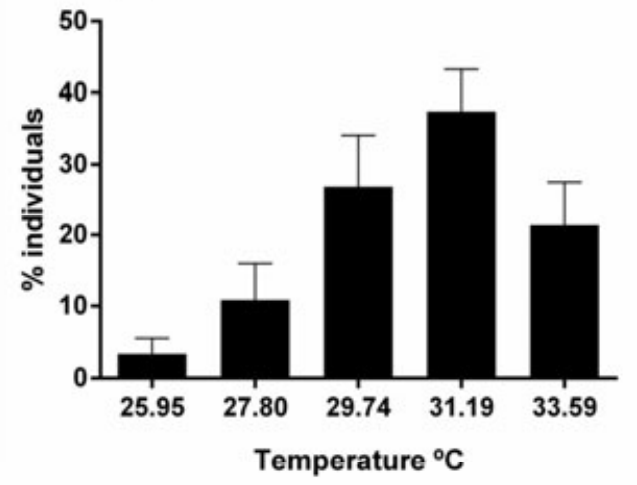

(b)

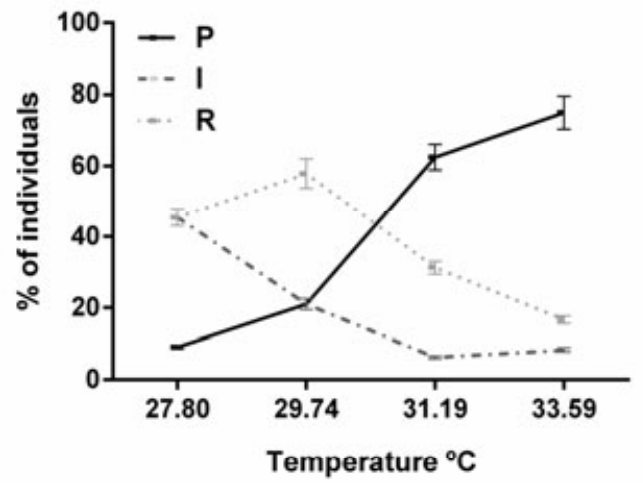

This article is protected by copyright. All rights reserved. 
Figure 5

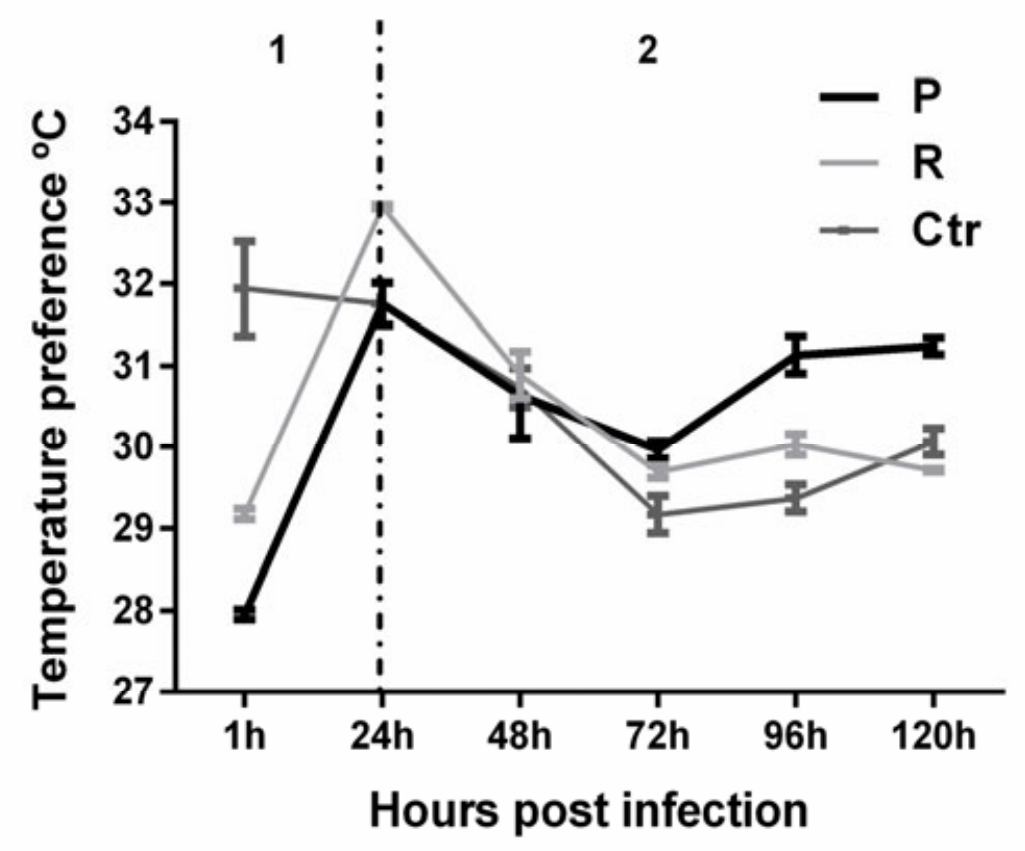

This article is protected by copyright. All rights reserved. 